\title{
КОНЦЕПЦИЯ «БОЛЬШОЙ БЛИЖНИЙ ВОСТОК» ПОД УГЛОМ НАЦИОНАЛЬНОЙ БЕЗОПАСНОСТИ
}

\begin{abstract}
Аннотация: В статье рассмотрена кониепџия «Большой Ближний Восток», представленная администрацией Буша-младщего в ноябре 2003 г. Она основана на идеи «демократизации» и «реконструкиии» Ближнего (Среднего) Востока и Северной Африки, где проводимая ранее политика США по поддержке авторитарных режимов во имя стабильности и безопасности не оправдала себя. $B$ ходе проведенных исследований выявлено, что другая конщепция - «Большая Центральная Азия» 8 значительной степени базировалась на идеях «Большого Ближнего Востока», но применительно $\kappa$ более ограниченному региону. Показано, что обе концепции стали неотъемлемой частью региональной политики США и при республиканцах, и при демократах. Отмечено, что деятельность США вела к дестабилизации ситуации на Ближнем (Среднем) Востоке и в Центральной Азии, что оказывало негативное влияние на состояние национальной безопасности Российской Федерации. Review: The article evaluates the Greater Middle East Concept as presented by the Administration of President Bush-junior in November 2003. It is based on the democratization and reconstruction of the Middle East and Northern Africa, where previously used US foreign policy on support of authoritarian regimes for the sake of stability and security failed. Based upon the analysis it was found out that the concept of the Greater Central Asia was to a great degree based upon the ideas of the Greater Middle East, but it was applied to a more limited region. It was shown that both concepts formed an inalienable part of the US regional policy for both the Republican and Democratic rule. It was noted that the activities of the USA led to destabilization of the situation in the Middle East and in the Central Asia, which had negative impact on the national security situation in the Russian Federation.
\end{abstract}

ключевые слова: Политология, Восток, США, реконструкиия, демократизация, Азия, Россия, безопасность, интересы, концепция

Keywords: political science, East, the USA, reconstruction, democratization, Asia, Russia, security, interests, concept.

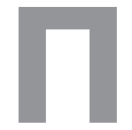

осле распада Советского Союза и становления однополярного мира внешняя политика США стала оказывать непосредственное воздействие на все государства. Мера такого воздействия определялась значимостью страны для американских национальных интересов. Ввиду зависимости Вашингтона от поставок нефти, такой интерес был явно проявлен к аравийским монархиям. Уязвимость основного американского союзника на Ближнем Востоке - Израиля требовала активной роли США как в этом регионе, так и на близлежащих территориях Северной Африки. Учитывая это, американские политологи постарались обосновать необходимость вмешательства США во внутренние дела всех этих государств. В результате появилась концепция «Большой
Ближний Восток». Как будет показано ниже, ее реализация оказала существенное влияние на национальную безопасность Российской Федерации ввиду создания (усиления) внешних угроз.

\section{Появление концепции «Большой Ближний Восток»}

Вооруженные силы США достаточно легко свергли власть С.Хуссейна в Ираке. У американской администрации это породило завышенные ожидания в отношении собственных возможностей по переустройству Ближнего Востока. Так, в начале мая 2003 г. президент Буш-младший, выступая перед выпускниками университета Южной Каролины, заявил о намерении «создать в течение десяти лет 
зону свободной торговли между США и Ближним Востоком ${ }^{1} »$. По его мнению, это позволило бы странам арабского мира «расширить круг возможностей» в сфере экономики и торговли, снизив свою зависимость от конъюнктуры нефтяного рынка. В частности, Дж. Буш-младший отметил: «Сменив коррупцию и корыстные сделки на свободные рынки и справедливые законы, народы Ближнего Востока приумножат процветание и свободу» ${ }^{2}$.

Представители республиканской администрации США тогда считали необходимым проведение на Ближнем Востоке демократических реформ и экономической либерализации «ради борьбы с бедностью и отсталостью, которые порождают терроризм». При этом военная операция США и их союзников в Ираке рассматривалась лишь как первый этап комплексной программы по «перестройке» указанного региона. Вашингтон стремился реализовать масштабный план, а именно: «усмирить» Ближний Восток путем установления там проамериканской «дружественной» демократии.

Вскоре стало ясно, что военного решения иракской проблемы не существует. Потребовалось компенсировать непопулярные силовые действия США конструктивной и привлекательной программой «светлого будущего» для этого стратегически важного региона. Именно поэтому, как полагает исследователь из Института Ближнего Востока А. Волович, в Белом доме возникла идея «демократизации» и «реконструкции» Ближнего Востока ${ }^{3}$.

Впервые план «реконструкции» Ближнего Востока был сформулирован президентом Бушеммладшим 6 ноября 2003 г. в его выступлении о «новой внешней политике» США в ближневосточном регионе, которое состоялось в Национальном фонде демократии ${ }^{4}$. По мнению президента США, реализуемая

\footnotetext{
${ }^{1}$ Американское понятие Ближний Восток включает также Ирак, государства Аравийского полуострова, Иран и Афганистан. В России принято называть этот регион Ближним и Средний Востоком.

${ }^{2}$ Bush G. Commencement Address at the University of South Carolina in Columbia, South Carolina. The American Presidency Project. [Electronic resource]. http://www.presidency.ucsb.edu/ws/ index.php?pid=407\#axzz1LD2PmQLn (May, 2003).

${ }^{3}$ Волович A.A. О планах демократизации Ближнего Востока [Электронный ресурс] // Институт Ближнего Востока. - М., 19 августа 2004 г. http://www.iimes.ru/?p=3269.

${ }^{4}$ Национальный фонд демократии был создан в 1983 г. президентом Рейганом и Конгрессом США «для укрепления демократических институтов во всем мире через воздействие на неправительственные институты».
}

им американская миссия - распространение свободы и демократии по всему миру - являлась логическим продолжением Версальского мирного договора, завершившего Первую мировую войну. Его основу составили «четырнадцать пунктов», предложенных президентом США Вильсоном. В январе 1941 г. подобное сделал Ф. Рузвельт в своем выступлении перед членами конгресса, которое получило название как речь о «четырех свободах».

В тот же день советник президента США по национальной безопасности К. Райс пояснила, что в прошлом внешняя политика Соединенных Штатов на Ближнем Востоке была обусловлена «холодной войной»: американцам приходилось закрывать глаза на то, что диктаторы творят внутри своих стран, если они придерживались проамериканских взглядов. Теперь президент США пришел к выводу, что политика поддержки авторитарных режимов во имя стабильности и безопасности не оправдала себя, поскольку привела к ухудшению обстановки в регионе.

Следует заметить, что Ближний Восток сразу стал трактоваться расширенно, как территория государств с преобладающим мусульманским населением: от Марокко до Пакистана включительно и от Турции до Судана. Так появилось понятие Большого Ближнего Востока, который стал включать Северную Африку, Ближний и Средний Восток, Турцию и Пакистан.

Основными авторами концепции «Большой Ближний Восток» стали Г. Киссинджер, Г. Допрет, Д. Рамсфельд, Д. Чейни, К. Райс, Р. Перл, П. Вулфовиц, М. Гроссман и другие американские политологи и представители исполнительной власти. Авторы указанной концепции исходили из того, что западная демократия как универсальное средство обеспечивает модернизацию, процветание, справедливость и диалог культур. Следовательно, на основе «реконструкции» Большого Ближнего Востока нужно создать такое сообщество, которое бы полностью отвечало национальным интересам США.

Основной замысел концепции «Большой Ближний Восток» был сформулирован следующим образом: «Решение палестинской проблемы через Багдад». Это свидетельствовало об участии в ее разработке произраильского лобби. И это не было случайным, так как именно указанная структура активно способствовала американскому вторжению в Ирак.

В соответствии с концепцией предполагалось сделать основную ставку на местные «реформаторские силы»: независимые средства массовой инфор- 
мации и комиссии по наблюдению за выборами, адвокатские конторы, группы правозащитников, женские организации и другие «независимые группы интересов», способные, как считалось, провести «свободные справедливые выборы». Помимо этого на Большом Ближнем Востоке планировалось осуществить экономическую либерализацию: высвобождение частной инициативы малого и среднего бизнеса, сокращение государственного регулирования и т.п.

\section{Реакция арабских стран}

Появление концепции «Большой Ближний Восток», которую квалифицировали как попытку вмешательства во внутренние дела, вызвало негативную реакцию у большинства арабских стран. С их стороны было отмечено, что демократические реформы должны стать результатом эволюционного развития арабских сообществ, а не навязываться извне. Одновременно американцев упрекнули в том, что предложенная концепция не содержит упоминания о необходимости разрешения арабо-израильского конфликта как предпосылки для проведения на Ближнем Востоке демократических реформ.

Президент Сирии Б. Асад сразу заявил, что не «может быть развития и демократии в условиях войны и существования политических проблем, и никто не только в Сирии, но и во всем регионе не верит в американскую инициативу». Лидер ливийской революции М. Каддафи назвал американскую инициативу «расистской», отметив, что «арабский Магриб не имеет никакого отношения к тому, что делается на Ближнем Востоке». Премьер-министр Кувейта шейх С. аль-Сабах проинформировал, что не приемлет попытки США построить Большой Ближний Восток с помощью навязывания социальных и экономических реформ. Некоторые представители арабских стран обвинили Вашингтон в том, что американская идея «реконструкции» Большого Ближнего Востока направлена, прежде всего, на обеспечение здесь интересов Израиля и США.

В противовес американской концепции на саммите Лиги арабских государств (ЛАГ), которой в мае 2004 г. прошел в Тунисе, Египет, Саудовская Аравия и Сирия выдвинули арабскую инициативу «самодемократизации» на основе следующих принципов:

1) реформирование «изнутри» самими арабскими обществами без навязывания извне;

2) постепенное реформирование без нарушения региональной безопасности и стабильности;
3) реформирование в интересах региона, а не врагов расположенных там государств;

4) необходимость разрешения арабо-израильского конфликта как обязательного условия успешного проведения в регионе политической реформы;

5) учет особенностей каждой арабской страны (реформы не могут проводиться по одному шаблону);

6) противодействие религиозным экстремистским группировкам в их попытке воспользоваться плодами проводимых реформ и политики «открытых дверей».

На этом саммите президент Египта Х. Мубарак предложил создать Межарабский механизм контроля, координации и консультаций. Это позволило бы путем постоянного диалога в рамках ЛАГ вырабатывать общую позицию по вопросам реформирования арабского мира и препятствовало вмешательству ведущих государств во внутренние дела стран Ближнего Востока под предлогом проведения там реформ. Однако президенты Сирии и Туниса не поддержали эту инициативу, что свидетельствовало об отсутствии межарабского единства. Последним не могли не воспользоваться исламисты, которые в период 2011-2012 гг. пришли к власти в Ливии и Египте, а ныне стремятся к ней в Сирии, Тунисе и Йемене.

\section{Взгляд со стороны Европы}

Концепция «Большой Ближний Восток» не нашла своего понимания и в Европе. Так, по мнению бывшего премьер-министра Франции Д. де Вильпена, «необходимо избегать универсального подхода, нельзя рассматривать страны Магриба по тому же сценарию, как со странами Ближнего Востока и странами Персидского залива. Нельзя концентрироваться на проблеме безопасности. Для достижения успеха, наш подход должен быть глобальным, с учетом всех политических, экономических, социальных, культурных, образовательных аспектов»5.

Как следствие, европейские государства, прежде всего Франция и Германия, предложили внести коррективы в указанную концепцию. В частности, Ж. Ширак неоднократно указывал, что партнерство между Западом и странами Большого Ближнего Востока должно быть результатом «свободного выбора». С его точки зрения, «страны Ближнего Востока и

\footnotetext{
${ }^{5}$ Haeri $S$. Concocting a «Greater Middle East» Brew. Asia Times. (March 3, 2004).
} 
Северной Африки не нуждаются в миссионерах для проведения демократизации» ${ }^{6}$.

В ходе интенсивных консультаций на протяжении несколько месяцев и с учетом позиции ЛАГ европейцы предложили внести изменения в американскую концепцию «Большой Ближний Восток». По их мнению, нельзя искусственно соединять в рамках указанной концепции такие разные страны как Афганистан, Пакистан, страны Персидского залива и Арабского Магриба. Европейцы опасались, что, приняв американский проект «модернизации» Большого Ближнего Востока, они будут вынуждены его финансировать. Последнее служило реализации лишь американских национальных интересов.

Тем не менее, во время саммита стран «Большой восьмерки», который в июне 2004 г. состоялся на американском острове Си-Айленд (штат Джорджия), европейцы согласились с необходимостью «реформирования» Большого Ближнего Востока. В окончательной редакции американская концепция получила название: «Партнерство ради прогресса и общего будущего с регионом Расширенного Ближнего Востока и Северной Африки». При этом были внесены существенные изменения в содержание исходного варианта. В экономической части концепции осталась лишь поддержка бизнеса в регионе, специальные кредиты мелким предпринимателям, особенно женщинам, борьба с неграмотностью и некоторые другие. По настоянию европейских и арабских стран в итоговый документ был внесен пункт о том, что помощь «Большой восьмерки» в проведении реформ на Ближнем Востоке и в Северной Африке Востоке должна происходить параллельно с содействием мирному урегулированию арабо-израильского конфликта на основе плана «дорожной карты», предусматривающего мирное сосуществование израильского и палестинского государств.

Помимо этого, в итоговый документ включили ряд положений, предложенных со стороны $\mathrm{OOH}$. В частности, было отмечено, что «существуют три области, требующие внимания со стороны мирового сообщества: отсутствие свободы, безграмотность и соблюдение прав женщин. Сохранение проблем в этих областях угрожают национальным интересам всех членов «Большой восьмерки» и приводит к

\footnotetext{
${ }^{6}$ Волович A.A. О планах демократизации Ближнего Востока [Электронный ресурс] // Институт Ближнего Востока. - М., 19 августа 2004 г. http://www.iimes.ru/?p=3269.
}

росту экстремизма, терроризма, международной преступности и незаконной миграции».

\section{Концепция «Большая Центральная Азия»}

Логическим продолжением американской политики на Ближнем и Среднем Востоке стало появление новой концепции - «Большая Центральная Азия». В значительной степени она базировалась на вышеописанных идеях «Большого Ближнего Востока», но применительно к более ограниченному региону, включающему Афганистан и страны Центральной Азии. В марте 2005 г. ее выдвинул американский исследователь Ф. Старр. Несмотря на критику со стороны большинства российских, европейских и центрально-азиатских экспертов, соответствующая концепция, как и предыдущая, стала неотъемлемой частью региональной политики США и при республиканцах, и при демократах.

Появление концепции «Большая Центральная Азия» было обусловлено тем обстоятельством, что американцы вновь переоценили процесс демократизации и становления государственности, но уже в Афганистане. Поэтому было заявлено о возможности улучшения экономического положения Центральной Азии за счет получения выхода на емкий рынок стран Южной Азии путем создания на афганской территории под контролем США транспортной инфраструктуры. Позднее, когда ситуация внутри Афганистана существенно ухудшилась, в Вашингтоне стали искать пути его стабилизации на основе развития экономических связей с государствами Центральной Азии. При этом суть американского подхода осталась той же: искусственное укрупнение региона с целью управления происходящими внутри него процессами.

Следует заметить, что Ф.Старр в своем аналитическом материале «Партнерство Большой Центральной Азии» для Афганистана и его соседей» обосновал необходимость для Вашингтона «содействия трансформации Афганистана и всего региона, ядром которого он является, в зону обеспеченных с точки зрения безопасности суверенных государств, разделяющих принципы жизнеспособной рыночной экономики, секулярных и относительно открытых систем правления, уважающих гражданские права и поддерживающих позитивные отношения с США. Появление этой зоны, которую с этого момента можно называть как «Большая Центральная Азия», отбросит силы, 


\section{Национальная безопасность 4(27) • 2013}

способствующие росту экстремизма, и усилит континентальную безопасность».

Фактически, автор предложил объединить центральноазиатские государства и Афганистан под контролем Вашингтона. По замыслу Ф.Старра, для этого было необходимо предоставить Афганистану и его соседям возможности защитить себя от радикального исламизма и наркоторговцев; укрепить региональную экономику и государственные институты до уровня, когда регион окажется способным служить в качестве экономического и политического моста между Ближним Востоком и Южной и Восточной Азией; упрочнить региональные торговые связи и транспортную инфраструктуру.

Кроме того была поставлена задача координации различных министерств и ведомств США для решения региональных внешнеполитических задач.

\section{Кризис американских концепций}

Несомненно, что концепция «Большой Ближний Восток» была взята на вооружение республиканской администрацией Буша-младшего. Однако, в силу ряда причин, реализовать ее американцы так и не смогли.

Во-первых, все попытки Вашингтона «демократизировать» Большой Ближний Восток вели только к усилению там нестабильности, фундаментализма и терроризма, что создавало внешние угрозы, в том числе для Российской Федерации. В частности, существуют неопровержимые факты участия граждан ряда мусульманских государств в боевых действиях против Объединенной группировки войск (сил) на Северном Кавказе.

Во-вторых, США не смогли создать в Ираке проамериканский режим. В итоге к власти в Багдаде пришли представители шиитского большинства, что привело к существенному улучшению ирано-иракских отношений.

B-третьих, американская концепция не была поддержана ни правительствами, ни народами стран Арабского Востока, а также Ирана и Турции. Единственная страна, которая не только поддерживает эту концепцию, но и постоянно «подталкивает» США к ее реализации - это Израиль, который считает себя «островком прозападной демократии среди автократического арабского моря».

В-четвертых в реформировании нуждался не столько Большой Ближний Восток, сколько отношения между расположенными там странами и
США (Западом в целом). Чем больше американцы вмешивались в дела Большого Ближнего Востока, использовали политику двойных стандартов и выступали гарантом некоторых режимов, тем сильнее росли в регионе антиамериканские отношения.

В-пятых, на территории постсоветского пространства реализацию этой концепции восприняли как продолжение американской политики «цветных» революций, что представляло уже непосредственную внутреннюю угрозу не только для стратегически важных для Москвы регионов Центральной Азии и Южного Кавказа, но и самой территории Российской Федерации. Несомненно, что это способствовало ослаблению национальной безопасности нашей страны.

Аналогичное произошло и по отношению к более частной концепции «Большая Центральная Азия». Так, российские эксперты заметили: Афганистан не может быть центром региона хотя бы потому, что его культурный уровень намного ниже расположенных в Центральной Азии государств. Именно Афганистан является очагом нестабильности, расширение его влияния только ухудшит положение в соседних странах.

Вместе с тем, рассмотренные идеи послужили обоснованием для американского вмешательства во внутренние дела государств Ближнего (Среднего) Востока, Северной Африки и Центральной Азии. И это импонировало республиканцам, которые решили переформатировать все указанные регионы. Как следствие, во время выступления в Национальном университете обороны в Вашингтоне, которое состоялось в начале марта 2005 г., президент Буш-младший заявил, что авторитарное правление, например, в государствах Центральной Азии, было «последним вздохом дискредитированного прошлого», а десятилетие апологетики тирании и компромиссов ради достижения стабильности породили лишь несправедливость, нестабильность и трагедию.

Американским планам не было суждено сбыться. Ситуация в Ираке и Афганистане все более ухудшалась, росли потери среди военнослужащих США, их союзников и партнеров. Сам факт присутствия последних в регионе стал рассматриваться как серьезный дестабилизирующий фактор, что требовало если не полного вывода, то хотя бы значительного сокращения численности иностранных войск.

Кроме того, «революция тюльпанов»в Киргизии в марте 2005 г. привела к отставке наиболее либерального и прозападного в регионе президента А. Акаева. Пришедший ему на смену 
К. Бакиев оказался авторитарным правителем, который стал лавировать между Россией, США и Китаем. А в мае 2005 г. произошли трагические события в узбекском городе Андижан. Их можно расценивать как вторую неудачную попытку «цветной революции», которая сопровождалась значительными жертвами среди местного населения. Узбекское руководство обвинило в организации этих событий западные неправительственные фонды. Как следствие сотрудничество с США было приостановлено, а их ВС были вынуждены покинуть военную базу «Карши-Ханабад». Позднее Узбекистан вступил в пророссийское Евразийское экономическое сообщество и Организацию Договора о коллективной безопасности.

\section{Позиция России}

Россию не могло не беспокоить то обстоятельство, что, как отмечает бывший советник президента США по национальной безопасности 3. Бжезинский, реализация концепции «Большой Ближний Восток» позволяла Вашингтону влиять на территории Евразийских Балкан, в состав которых были включены Южный Кавказ, Центральная Азия, Афганистан, Турция и Пакистан ${ }^{7}$. В этом случае возникала прямая угроза национальной безопасности Российской Федерации в стратегически важных для нее регионах.

Учитывая, что деятельность американцев вела к дестабилизации ситуации на Ближнем (Среднем) Востоке и в Центральной Азии, а их военные базы угрожали национальной безопасности в долгосрочном плане, Россия стала препятствовать сохранению военных баз США на постоянной основе вблизи собственной территории. Это нашло, в частности, свое отражение в декларации, которая была принята в июле 2005 г. на саммите Шанхайской организации сотрудничества в Астане. В качестве ответной меры Палата представителей Конгресса Соединенных Штатов приняла резолюцию с выражением озабоченности «явной попыткой Китая и России выдавить США из региона» ${ }^{8}$.

\footnotetext{
${ }^{7}$ Следует заметить, что понятия Большой Ближний Восток и Евразийские Балканы частично пересекаются. Так, оба эти понятия включают Афганистан, Турцию и Пакистан.

8 Дубнов А. Узбекские интересы пролоббируют в Вашингтоне // Время новостей. М., 25 июля 2005 г.
}

Конечно, Россия не могла помешать США реализовывать концепцию «Большой Ближний Восток». Основная причина этого состояла в ограниченности имеющихся ресурсов и существенном сокращении своего влияния в рассматриваемых регионах в 90-е годы. Тогда у многих в Москве существовали иллюзии по отношению к Западу и явно недооценивались собственные возможности. Сейчас ситуация изменилась, но вернуться на Ближний и Средний Восток намного труднее, чем оттуда уйти. В меньшей степени это имеет отношение к Центральной Азии.

С учетом складывавшейся ситуации российское руководство заняло единственно правильную позицию: постепенное восстановление двусторонних отношений с расположенными в рассматриваемых регионах странами, установление (развитие) контактов не только с действующей властью, но и оппозицией, политическое и экономическое сотрудничество на двустороннем и многостороннем уровне, избежание прямого столкновения с американскими национальными интересами, а также активное участие в арабоизраильском урегулировании. Достаточно неудачные попытки США реализовывать концепцию «Большой Ближний Восток» создавали для этого благоприятный фон, так как усиливали антиамериканские настроения даже среди своих региональных союзников, исключая Израиль.

\section{«Арабская весна»}

Вопреки мнению многих, «арабская весна», которая началась в январе 2011 г. с отстранения от власти проамериканского президента 3. Бен Али в Тунисе, для Вашингтона стала неожиданностью. Конечно, попытки реализации концепции «Большой Ближний Восток» ухудшали внутриполитическую ситуацию стран Ближнего (Среднего) Востока и Северной Африки. Но в Вашингтоне надеялись удержать ситуацию по контролем даже после отстранения от власти в Египте еще одного их союзника - Х. Мубарака.

На Западе, особенно на начальном этапе, часто сравнивали «арабскую весну» с событиями в Восточной Европе конца 80-х - начала 90-х годов. И в том, и в другом случае смысл происходивших событий сводился к демонтажу государственно-политических структур, сформировавшихся в период «холодной войны». На волне эйфории от ранее достигнутой победы Запад сделал ставку на всемерную поддержку демократических тенденций. Однако смена элит, сопровождавшаяся завышенными со- 
циально-экономическими ожиданиями населения, оказалась более благоприятной для прихода к власти не демократов, а исламистов. Американцы, которые еще с 80-х годов имели устойчивые связи с умеренными исламистами, были готовы к такому развитию событий. Но молодые «зеленые» демократии быстро показали, что они имеют собственные программы, далеко не всегда совпадающие со взглядами из Вашингтона. Более того, сентябрьские (2012 г.) погромы американских дипломатических представительств, прокатившиеся по всему исламскому миру, взбудоражили не только Европу, но и другие континенты. Убийство американского посла К.Стивенса и трех его коллег в Бенгази только довершило общую тревожную картину.

По сути, вышеизложенное означало крах ранее предложенной концепции «Большой Ближний Восток». Однако в Вашингтоне отказываться от нее не собираются. В этом отношении показательно высказывание сенатора, а ныне Государственного секретаря США Дж.Керри. По его мнению, волна демократических восстаний на Ближнем Востоке и в Северной Африке является «одним из самых знаменательных событий нашего времени...Свержение авторитарных режимов в Тунисе и Египте открыло путь к созданию более прозрачного и ответственного правительства, и США играют решающую роль в обеспечении этих демократических преобразований».

В качестве основных направлений развития политики США на Большом Ближнем Востоке Дж. Керри предложил следующие:

a) развитие демократии;

В Вашингтоне полагают, что политические реформы служат не только интересам протестующих, которые требуют смены правительств на более «прозрачные», то есть лишенные коррупции и подотчетные собственному народу. Это позволяет упреждать потенциальные угрозы для национальной безопасности США, в том числе путем реализации программ помощи и поддержки демократии. Ввиду пессимизма конгресса по вопросу осуществления программ помощи иностранным государствам сенатор Керри предупредил: «Мы можем либо оказывать финансовую помощь сейчас, либо оказывать ее позже, но уже в условиях повышенной угрозы для нашей национальной безопасности».

б) учет уроков, полученных после распада Советского Союза;

Дж. Керри полагает, что распад Советского Союза может стать историческим примером для развития отношений США со странами постреволюционного Большого Ближнего Востока;

в) поддержка и развитие рыночной экономики.

В Сенате США разрабатывается новая законодательная база для экономик стран - новых демократий, включая страны Большого Ближнего Востока9.

Конечно, подходы демократа Керри к процессам, происходящим на Ближнем (Среднем) Востоке и в Северной Африке, намного более взвешенные, чем это делалось во времена Дж. Буша-младшего. Американцы, скорее всего, отказались от «реконструкции» Большого Ближнего Востока. Однако на повестке дня остается вопрос о его «демократизации», хотя и не в качестве высшего приоритета. Следовательно, для США концепция «Большой Ближний Восток», пусть и в измененном виде, все еще сохраняет свою актуальность. И это создает дополнительные риски для всех проживающих там народов, способствуя ослаблению национальной безопасности Российской Федерации.

\section{Будущее Большого Ближнего Востока}

Несомненно, что нынешний Большой Ближний Восток напоминает минное поле потенциальных этнических и пограничных конфликтов, готовых взорваться при любом неосторожном движении. При этом, как отмечает Чрезвычайный и Полномочный Посол России П. Стегний, существуют два основных сценария дальнейшего развития событий ${ }^{10}$ :

а) версальский;

После Первой мировой войны «передел Европы» сопровождался разделом арабских владений Османской империи при ведущей роли внешних сил. США надеются, что благодаря своему экономическому, политическому и военному влиянию они при поддержке союзников смогут контролировать процессы на Большом Ближнем Востоке. По-видимому, американцы завышают собственные возможности и слишком верят в притягательную силу демократии по западному типу. Попытки вмешательства

\footnotetext{
${ }^{9}$ Muasher M. Senator John Kerry on U.S. Policy Toward the Middle East. Carnegie Endowment for International Peace. [Electronic resource]. http://www.carnegieendowment.org/2011/03/16/senatorjohn-kerry-on-u.s.-policy-toward-middle-east/ $1 \mathrm{fd}$.

${ }^{10}$ Стегний П.В. Ближний Восток: по-версальски или повестфальски? [Электронный ресурс] // Российский совет по международным делам. - М., 23 декабря 2012 г. http:// russiancouncil.ru/inner/?id_4=1232\#top.
} 
Вашингтона во внутренние дела расположенных там государств уже привели к небывалому росту антиамериканских настроений. Скорее всего, эта тенденция сохранится и после корректировки Б. Обамой региональной политики США, что будет означать реальное сокращение их сферы влияния.

б) вестфальский.

Вестфальский мир (1648 г.) завершил Тридцатилетнюю войну в Священной Римской империи. Он положил началу нового порядка в Европе, основанному на концепции государственного суверенитета. По отношению к Большому Ближнему Востоку это означает, что судьбоносные для народов решения будут приниматься самими региональными странами без внешнего вмешательства и при строгом соблюдении требований международного права. Россия призывает именно к такому развитию событий, что полностью отвечает интересам народов Ближнего (Среднего) Востока и Северной Африки. Но Запад еще слишком силен, а его лидеры уверены в собственном могуществе. Следовательно, реализовать указанный сценарий будет крайне сложно.

Несомненно, что крушение авторитарных режимов на Большом Ближнем Востоке, начавшееся в ходе «арабской весны», может стать очередным этапом единого исторического процесса. Вслед за Восточной Европой и Балканами Большой Ближний Восток способен вступить в сообщество государств, отношения между которыми базируются на единых ценностях. Но для этого необходимо встречное движение со стороны Запада, его согласие играть по единым правилам формирующегося многополярного мира, уважение к религиозным чувствам местного населения, безусловное соблюдение государственного суверенитета и отказ от попыток подмены его соображениями политической целесообразности. Соединенные Штаты как лидер западного мира к этому еще не готовы, поэтому они не отказываются от концепции «демократизации» Большого Ближнего Востока. Это будет создавать в странах Ближнего (Среднего) Востока и Северной Африки значительную нестабильность, что негативно повлияет на безопасность не только европейских государств, но и самих США.

Таким образом, провозглашенная в ноябре 2003 г. концепция «Большой Ближний Восток» все еще сохраняется свою актуальность. Это обусловлено стремлением США к распространению демократии как универсального средства борьбы с терроризмом, коррупцией, бедностью и другими социально-экономическими проблемами. Многим в Вашингтоне кажется, что весь мир только и ждет от них помощи в построении общества по западному образцу. На самом деле это далеко не так. Западные идеалы все более бледнеют на фоне усиления центробежных процессов в Европейском союзе, экономической стагнации, нарастания внутреннего протеста и религиозной нетерпимости. Постепенно, но неумолимо падает международный авторитет США, что сокращает сферу их влияния. Для Запада в целом это является крайне тревожным сигналом, не заметить который уже просто невозможно.

Тем не менее, американцы продолжают цепляться за уходящее могущество, пытаясь весь мир подстроить под себя. В первую очередь это имеет отношение к Ближнему и Среднему Востоку - важнейшему источнику углеводородных ресурсов. Именно здесь Соединенным Штатам нужны лояльные и управляемые режимы. В связи с этим, появление во время правления администрации Буша-младшего концепции «Большой Ближний Восток» не было случайным. В Вашингтоне посчитали возможным осуществить «реконструкцию» этого региона, но встретили жесткое сопротивление как со стороны своих региональных (Саудовская Аравия, Египет), так и европейских союзников. В итоге пришлось ограничится полумерами, что только дискредитировало предложенную концепцию.

Демократическая администрации Обамы отказалась от жесткого давления и обратились к использованию «умной» силы. В рамках концепции «Большой Ближний Восток» это означало переход от «реконструкции» к «демократизации», что, по сути, не меняло прежнего подхода. Приход так называемой «арабской весны», на первый взгляд, создавал для американцев новые возможности. Но их вновь ждало разочарование: демократическую оппозицию достаточно быстро оттеснили хорошо организованные исламисты - стратегические противники западного мира.

Несомненно, что политика США, направленная на реализацию взаимосвязанных концепций «Большой Ближний Восток» и «Большая Центральная Азия», оказала негативное влияние на состояние национальной безопасности Российской Федерации. Однако, степень американского влияния в рамках указанных концепций была различной. Так, на Ближнем и Среднем Востоке Москва лишь восстанавливала свое влияние, поэтому ей приходилось 
избегать прямого противостояния с США. Это не исключало борьбу за собственные интересы, например, в Сирии, но предполагало ведение с Западом постоянного диалога. Несколько иначе складывалась ситуация в Центральной Азии, где Россия по праву является одним из основных внешнеполитических игроков. Однако и здесь диалог с США был необходим, но уже на равных условиях. В целом такая политика позволяла Российской Федерации обеспечивать национальную безопасность на достаточно высоком уровне. Следовательно, она должна быть продолжена.

\section{Библиография:}

1. Ашимбаев М. Современный геополитическая ситуация в Центральной Азии в контексте интересов мировых и региональных держав / Сотрудничество стран Центральной Азии и США по обеспечению безопасности в регионе. Материалы международной конференции // Под ред. М. Ашимбаева и Дж. Меннути. - Алматы, 2005.

2. Братерский М.В. США и проблемные страны Азии: обоснование, выработка и реализация политики в 1990 - 2005 гг. - М.: МОНФ - Институт США и Канады РАН, 2005 г.

3. Казанцев А.А. «Большая игра» с неизвестными правилами: мировая политика и Центральная Азия / Некоммерческий фонд «Наследие Евразии». - М, 2008.

4. Касаев Э. Шансы демократии в Ираке // Международные процессы. М., 2008. Т. 6. № 2.

5. Кургинян С., Бялый Ю., Кудинова А., Кургинян И. и др. Политическое цунами. Аналитика событий в Северной Африке и на Ближнем Востоке / Под ред. С.Кургиняна. М.: МОФ ЭТЦ, 2011.

6. Лаумулин М.Т. Центральная Азия в зарубежной политологии и мировой политике. Т. 2. Алматы, 2006.

7. Султанов Б. Партнерские отношения РК и США в борьбе с терроризмом и экстремизмом / Сотрудничество стран Центральной Азии и США по обеспечению безопасности в регионе. Материалы международной конференции // Под ред. М. Ашимбаева и Дж. Меннути. Алматы, 2005.

8. Brzezinski Z. The Grand Chessboard: American Primacy and Its Geo-strategic Imperatives. Basic Books (Sept., 1998).
9. Greater Middle East Partnership. Al-Hayat (Feb. 13, 2004).

10. Starr S.F. A «Greater Central Asia Partnership» for Afghanistan and Its Neighbors Silk Road Paper. Central Asia-Caucasus Institute \& Silk Road Studies Program - A Joint Transatlantic Research and Policy Center Johns Hopkins University. Washington, D.C. (March 2005).

\section{References (transliteration):}

1. Ashimbaev M. Sovremennyy geopoliticheskaya situaciya v Central'noy Azii v kontekste interesov mirovyh i regional'nyh derzhav / Sotrudnichestvo stran Central'noy Azii i SShA po obespecheniyu bezopasnosti $\mathrm{v}$ regione. Materialy mezhdunarodnoy konferencii // Pod red. M. Ashimbaeva i Dzh. Mennuti. - Almaty, 2005.

2. Braterskiy M.V. SShA i problemnye strany Azii: obosnovanie, vyrabotka i realizaciya politiki v 1990 - 2005 gg. - M.: MONF - Institut SShA i Kanady RAN, $2005 \mathrm{~g}$.

3. Kazancev A.A. «Bol'shaya igra» s neizvestnymi pravilami: mirovaya politika i Central'naya Aziya / Nekommercheskiy fond «Nasledie Evrazii». - M, 2008.

4. Kasaev E. Shansy demokratii v Irake // Mezhdunarodnye processy. M., 2008. T. 6. № 2.

5. Kurginyan S., Byalyy Yu., Kudinova A., Kurginyan I. i dr. Politicheskoe cunami. Analitika sobytiy v Severnoy Afrike i na Blizhnem Vostoke / Pod red. S.Kurginyana. M.: MOF ETC, 2011.

6. Laumulin M.T. Central'naya Aziya v zarubezhnoy politologii i mirovoy politike. T. 2. Almaty, 2006.

7. Sultanov B. Partnerskie otnosheniya RK i SShA v bor'be s terrorizmom i ekstremizmom / Sotrudnichestvo stran Central'noy Azii i SShA po obespecheniyu bezopasnosti $\mathrm{v}$ regione. Materialy mezhdunarodnoy konferencii // Pod red. M. Ashimbaeva i Dzh. Mennuti. Almaty, 2005.

8. Brzezinski Z. The Grand Chessboard: American Primacy and Its Geo-strategic Imperatives. Basic Books (Sept., 1998).

9. Starr S.F. A «Greater Central Asia Partnership» for Afghanistan and Its Neighbors Silk Road Paper. Central Asia-Caucasus Institute \& Silk Road Studies Program - A Joint Transatlantic Research and Policy Center Johns Hopkins University. Washington, D.C. (March 2005). 